\title{
Comparison between the Effectiveness of Oral Phloroglucin and Cimetropium Bromide as Premedication for Diagnostic Esophagogastroduodenoscopy: An Open-Label, Randomized, Comparative Study
}

\author{
Hye-Won Yun, Ki-Nam Shim, Sun-Kyung Na, Jae-In Ryu, Min-Jin Lee, Eun-Mi Song, Seong-Eun Kim, \\ Hye-Kyoung Jung and Sung-Ae Jung \\ Department of Internal Medicine, Ewha Medical Research Institute, Ewha Womans University School of Medicine, Seoul, Korea
}

\begin{abstract}
Background/Aims: Suppression of gastrointestinal (GI) peristalsis during GI endoscopy commonly requires antispasmodic agents such as hyoscine butylbromide, atropine, glucagon, and cimetropium bromide. This study examined the efficacy of oral phloroglucin for the suppression of peristalsis, its impact on patient compliance, and any associated complications, and compared it with intravenous or intramuscular cimetropium bromide administration.

Methods: This was a randomized, investigator-blind, prospective comparative study. A total of 172 patients were randomized into two groups according to the following medications administered prior to upper endoscopy: oral phloroglucin (group A, $n=86$ ), and cimetropium bromide (group B, $n=86$ ). The numbers and the degrees of peristalsis events at the antrum and second duodenal portion were assessed for 30 seconds.

Results: A significantly higher number of gastric peristalsis events was observed in group A $(0.49$ vs. $0.08, p<0.001)$, but the difference was not clinically significant. No significant difference between both groups was found in the occurrence of duodenal peristalsis events ( 1.79 vs. $1.63, p=0.569)$. The incidence of dry mouth was significantly higher with cimetropium bromide than with phloroglucin ( $50 \%$ vs. $15.1 \%, p<0.001)$.
\end{abstract}

Conclusions: Oral phloroglucin can be used as an antispasmodic agent during upper endoscopy, and shows antispasmodic efficacy and adverse effects similar to those of cimetropium bromide.

Key Words: Upper endoscopy; Phloroglucin; Cimetropium

\section{INTRODUCTION}

Upper endoscopy facilitates the detection and treatment of gastrointestinal (GI) disease. Antispasmodic agents such as hyoscine butylbromide, atropine, glucagon, cimetropium bromide, and L-menthol are often administered prior to GI endoscopy to inhibit peristalsis and improve visualization. ${ }^{1,2}$

Received: February 10, 2014 Accepted: March 6, 2014

Correspondence: Ki-Nam Shim

Department of Internal Medicine, Ewha Medical Research Institute, Ewha Womans University School of Medicine, 1071 Anyangcheon-ro, Yangcheon-gu, Seoul 158-710, Korea

Tel: +82-2-2650-5887, Fax: +82-2-2655-2076, E-mail: shimkn@ewha.ac.kr

(c) This is an Open Access article distributed under the terms of the Creative Commons Attribution Non-Commercial License (http://creativecommons.org/ licenses/by-nc/3.0) which permits unrestricted non-commercial use, distribution, and reproduction in any medium, provided the original work is properly cited.
However, these agents must be administered intravenously or intramuscularly and may cause adverse effects such as dry mouth, urinary retention, temporary impairment of visual accommodation, palpitations, anaphylactic shock, and hyperglycemia. ${ }^{3-5}$ Cimetropium bromide (Algiron; Boehringer Ingelheim $\mathrm{GmbH}$, Ingelheim, Germany) is used particularly frequently in South Korea. Cimetropium bromide can cause pain and preprocedural anxiety due to its administration by intravenous or intramuscular injection, the preparation of which is time-consuming. ${ }^{6,7}$

Phloroglucin (Flospan; Daehwa Pharmaceutical, Seoul, Korea), administered orally, was expected to reduce pain and discomfort more effectively than intravenous or intramuscular injections of other antispasmodic agents. However, few studies of its usefulness as an endoscopic premedication have 
been performed.

In this study, we examined the efficacy of oral phloroglucin for the suppression of peristalsis, its impact on patient compliance, and any associated complications, and compared it with the intravenous or intramuscular administration of cimetropium bromide.

\section{MATERIALS AND METHODS}

This was a randomized, investigator-blind, prospective comparative study. From August 2012 through May 2013, we enrolled 174 patients who visited the Ewha Womans University Mokdong Hospital. Eligible patients were aged 18 years or older and scheduled to be examined by esophagogastroduodenoscopy. Patients with a history of upper GI surgery, GI bleeding, pregnancy, or contraindications for anticholinergic agents (glaucoma, myasthenia gravis, and urinary obstruction) were excluded from the study. Written informed consent was obtained from all subjects before enrollment. This study was approved by the Ewha Womans University's Ethics Committee.

Patients were randomized into two groups according to the following medications administered prior to upper endoscopy: oral phloroglucin (group A) and cimetropium bromide (group B). All endoscopic procedures were performed by a single experienced endoscopists who was blinded to the patients' group assignments. We evaluated total procedure times (from insertion to removal), total number of peristalsis events (stomach and duodenal motility numbers, counted at the antrum and duodenal second portion for 30 seconds each), and patient responses to questionnaires assessing tolerance and adverse events during the procedure (mouth dryness, nausea, vomiting, dizziness, headache, and abdominal pain). The degree of peristalsis was assessed using visibility scores (range, 0 to 2 ) at the antrum and duodenal second portion ( 0 , no peristalsis; 1 , slight peristalsis but no obscured visibility; 2 , severe peristalsis with obscured visibility).

\section{Statistical analysis}

Demographic characteristics and visibility scores were assessed using the chi-square test and Student $t$-test. A $p$-value $<0.05$ was considered statistically significant.

\section{RESULTS}

Among the 174 patients enrolled in the study, two were excluded because of severe duodenal stenosis. The remaining 172 patients were randomized into two groups according to medication administered prior to upper endoscopy, namely oral phloroglucin (group A, $n=86$ ) or cimetropium bromide (group B, $n=86$ ). The demographic and other baseline characteristics of included patients are shown in Table 1. There was no statistically significant difference between the two groups regarding age, sex, medical history (with the exception of thyroid disease), and the proportion of patients taking sedatives for endoscopy.

The incidence and degree of peristalsis in each group is presented in Table 2 . A significantly higher number of gastric peristalsis events was seen in group A $(0.49 \pm 0.85$ vs. $0.08 \pm$ $0.28, p<0.001$ ), but the number of events was fewer than one in both groups, and the difference was not clinically significant. The degree of peristalsis of the stomach was significantly lower in group B ( $1.14 \pm 0.38$ vs. $1.00, p=0.001)$, but both groups had visibility scores of approximately 1 , with a clinically insignificant difference. No significant between-group difference was found for the number of duodenal peristalsis events ( $1.79 \pm 2.0$ vs. $1.63 \pm 1.8, p=0.569$ ). The degree of peristalsis of the duodenum did not differ significantly between the groups

Table 1. Demographic Characteristics of Patients in Each Group

\begin{tabular}{lccc}
\hline \multicolumn{1}{c}{ Characteristic } & Oral & Cimetropium & \\
& phloroglucin & bromide & -value \\
\hline Number & 86 & 86 & \\
Age, yr & $49.4 \pm 16.3$ & $47.8 \pm 16.8$ & 0.508 \\
Sex, male/female & $42 / 44$ & $39 / 47$ & 0.760 \\
Medical history & & & \\
$\quad$ Diabetes mellitus & $5(5.8)$ & $6(7.0)$ & 1.000 \\
$\quad$ Hypertension & $17(19.8)$ & $14(16.3)$ & 0.692 \\
$\quad$ Thyroid disease & 0 & $7(8.1)$ & 0.014 \\
$\quad \begin{array}{l}\text { Malignancy } \\
\text { Irritable bower }\end{array}$ & $5(5.8)$ & $5(5.8)$ & 1.000 \\
$\quad$ syndrome & $3(3.5)$ & $3(3.5)$ & 1.000 \\
$\quad$ Abdominal operation & $34(39.5)$ & $40(46.5)$ & 0.440 \\
$\quad$ history & & & \\
Sedative endoscopy & $56(65.1)$ & $59(68.6)$ & 0.746 \\
Biopsy & $34(39.5)$ & $40(46.5)$ & 0.441 \\
\hline
\end{tabular}

Values are presented as mean \pm SD or number (\%).

Table 2. The Number and Degree of Peristalsis Events in Each Group

\begin{tabular}{lccc}
\hline \multicolumn{1}{c}{ Variable } & Oral & Cimetropium & \\
& phloroglucin & bromide & $p$-value \\
\hline Stomach & & & \\
$\quad$ No. of peristalsis & $0.49 \pm 0.85$ & $0.08 \pm 0.28$ & $<0.001$ \\
$\quad$ Degree of peristalsis & $1.14 \pm 0.38$ & $1.0 \pm 0$ & 0.001 \\
$\quad \begin{array}{lll}\text { Duodenum } \\
\quad \text { No. of peristalsis }\end{array}$ & $1.79 \pm 2.0$ & $1.63 \pm 1.8$ & 0.569 \\
$\quad$ Degree of peristalsis & $1.21 \pm 0.4$ & $1.15 \pm 0.39$ & 0.342 \\
\hline
\end{tabular}

Values are presented as mean $\pm \mathrm{SD}$. 
Table 3. The Number and Degree of Peristalsis Events according to Biopsy

\begin{tabular}{|c|c|c|c|c|c|c|}
\hline \multirow[b]{2}{*}{ Variable } & \multicolumn{3}{|c|}{ Biopsy } & \multicolumn{3}{|c|}{ Non-biopsy } \\
\hline & Oral phloroglucin & $\begin{array}{l}\text { Cimetropium } \\
\text { bromide }\end{array}$ & $p$-value & Oral phloroglucin & $\begin{array}{l}\text { Cimetropium } \\
\text { bromide }\end{array}$ & $p$-value \\
\hline Number & 34 & 40 & & 52 & 46 & \\
\hline Examination time, min & $6.80 \pm 2.10$ & $6.14 \pm 2.22$ & 0.197 & $4.28 \pm 1.30$ & $4.19 \pm 1.01$ & 0.715 \\
\hline \multicolumn{7}{|l|}{ Stomach } \\
\hline Number & $0.59 \pm 0.82$ & $0.03 \pm 0.16$ & $<0.001$ & $0.42 \pm 0.87$ & $0.13 \pm 0.34$ & 0.029 \\
\hline Degree & $1.15 \pm 0.36$ & $1.00 \pm 0$ & 0.012 & $1.13 \pm 0.40$ & $1.00 \pm 0$ & 0.018 \\
\hline \multicolumn{7}{|l|}{ Duodenum } \\
\hline Number & $2.03 \pm 2.12$ & $1.73 \pm 1.77$ & 0.503 & $1.63 \pm 1.84$ & $1.54 \pm 1.82$ & 0.806 \\
\hline Degree & $1.21 \pm 0.41$ & $1.18 \pm 0.45$ & 0.759 & $1.21 \pm 0.41$ & $1.13 \pm 0.34$ & 0.289 \\
\hline
\end{tabular}

Values are presented as mean $\pm \mathrm{SD}$.

Table 4. Adverse Events in Each Group

\begin{tabular}{lccr}
\hline Adverse events & $\begin{array}{c}\text { Oral } \\
\text { phloroglucin }\end{array}$ & $\begin{array}{c}\text { Cimetropium } \\
\text { bromide }\end{array}$ & $p$-value \\
\hline Dry mouth & $13(15.1)$ & $43(50)$ & $<0.001$ \\
Nausea, vomiting & $5(5.8)$ & $8(9.3)$ & 0.566 \\
Dizziness & $33(38.4)$ & $36(41.9)$ & 0.756 \\
Drowsiness & $16(18.6)$ & $20(23.3)$ & 0.574 \\
Headache & $5(5.8)$ & $2(2.3)$ & 0.443 \\
Dysuria & $2(2.3)$ & 0 & 0.497 \\
\hline
\end{tabular}

Values are presented as number (\%).

( $1.21 \pm 0.4$ vs. $1.15 \pm 0.39, p=0.342)$. There was no significant difference between the groups in total procedure time (5.28 \pm 2.07 minutes vs. $5.10 \pm 1.94$ minutes, $p=0.563$ ). The incidence and degree of peristalsis and procedure time were not different between patients who received a biopsy and those who did not (Table 3).

Tolerance of endoscopy was not significantly different between the two groups, and the same number of patients tolerated the procedure well in both groups (group A, $n=75,87.2 \%$; group $\mathrm{B}, n=75,87.2 \%)$. No serious adverse events occurred in the course of the study. The incidence of adverse effects is presented in Table 4 . The incidence of dry mouth was significantly higher with cimetropium bromide than with phloroglucin (50\% vs. $15.1 \%, p<0.001$ ). No significant between-group differences were noted for the incidence of other adverse events such as nausea, vomiting, dizziness, headache, dysuria, and abdominal pain.

\section{DISCUSSION}

Cimetropium bromide (Algiron) is often used before GI endoscopy to inhibit peristalsis and improve visualization, and is particularly popular in South Korea. However, cimetropium bromide causes pain and preprocedural anxiety due to its administration by intravenous or intramuscular injection, the preparation of which is time-consuming.

This study showed that oral phloroglucin is somewhat inferior to cimetropium bromide in the suppression of gastric peristalsis, but the difference was not clinically significant because the number of peristalsis events was less than one in both groups, and the degree of peristalsis was approximately grade 1 in both groups. In this study, we demonstrated that oral phloroglucin is not inferior to cimetropium bromide in the inhibition of peristalsis during endoscopy. In addition, endoscopic examination using oral phloroglucin was associated with similar procedure times, tolerance of endoscopy, and adverse events profiles. Furthermore, phloroglucin is superior to cimetropium bromide with respect to the incidence of dry mouth. An important advantage of oral phloroglucin is its ease of administration, effective suppression of peristalsis during endoscopy, and reduction in the incidence of dry mouth. Our findings suggest that oral phloroglucin can be used for the suppression of gastroduodenal peristalsis during upper endoscopy.

Our study had some limitations. We did not examine the effect of phloroglucin during endoscopic procedures such as endoscopic mucosal resection, endoscopic submucosal dissection, endoscopic retrograde cholangiopancreatography, and colonoscopy. Further studies are needed to examine the effects of oral phloroglucin during a variety of endoscopic therapeutic procedures and colonoscopy.

In conclusion, oral phloroglucin can be used as an antispasmodic agent during upper GI endoscopy with similar antispasmodic efficacy and fewer adverse effects when compared with cimetropium bromide.

\section{Conflicts of Interest}

The authors have no financial conflicts of interest. 


\section{REFERENCES}

1. Lee JY, Kim SJ, Choi CS, et al. The efficacy of cimetropium bromide as a premedication before esophagogastroduodenoscopy. Korean J Gastrointest Endosc 2008;37:403-408.

2. Hiki N, Kaminishi M, Yasuda K, et al. Antiperistaltic effect and safety of L-menthol sprayed on the gastric mucosa for upper GI endoscopy: a phase III, multicenter, randomized, double-blind, placebo-controlled study. Gastrointest Endosc 2011;73:932-941.

3. Hiki N, Kurosaka H, Tatsutomi Y, et al. Peppermint oil reduces gastric spasm during upper endoscopy: a randomized, double-blind, doubledummy controlled trial. Gastrointest Endosc 2003;57:475-482.

4. Treweeke P, Barrett NK. Allergic reaction to Buscopan. Br J Radiol
1987;60:417-418.

5. Goei R, Nix M, Kessels AH, Ten Tusscher MP. Use of antispasmodic drugs in double contrast barium enema examination: glucagon or buscopan? Clin Radiol 1995;50:553-557.

6. Pfeiffer A, Kaess H, Bödeker RH, Schwantes U. Heart rate increase after intravenous administration of trospium chloride and scopolamine during endoscopic retrograde cholangiopancreatography. Endoscopy 1999; 31:507.

7. Hasselkus W. Inappropriate rise in heart rate caused by intravenous administration of trospium chloride during upper gastrointestinal endoscopy. Endoscopy 1998;30:580. 